Southern Illinois University Carbondale

OpenSIUC

Publications

Educational Psychology and Special Education

2013

\title{
Erring on the side of life: Children with rare trisomy conditions, medical interventions and quality of life
}

Deborah Bruns

Southern Illinois University Carbondale, dabruns@siu.edu

Follow this and additional works at: http://opensiuc.lib.siu.edu/epse_pubs

Published in Journal of Genetic Disorders \& Genetic Reports, Vol. 2 No. 1 (2013) at doi: 10.4172/

2327-5790.1000103

\section{Recommended Citation}

Bruns, Deborah. "Erring on the side of life: Children with rare trisomy conditions, medical interventions and quality of life." (Jan 2013).

This Article is brought to you for free and open access by the Educational Psychology and Special Education at OpenSIUC. It has been accepted for inclusion in Publications by an authorized administrator of OpenSIUC. For more information, please contact opensiuc@lib.siu.edu. 


\section{Journal of Genetic Disorders \& Genetic

\section{Erring on the Side of Life: Children with Rare Trisomy Conditions, Medical Interventions and Quality of Life}

Deborah A. Bruns ${ }^{1 *}$

\begin{abstract}
The prevailing viewpoint on children with rare trisomy conditions such as trisomy 18 (t18) and trisomy 13 (t13) is almost uniformly negative. Yet, case studies offer information about long-term survivors. What is missing in the discussion is an unbiased examination of surviving children within the context of necessary, rather than "aggressive", medical interventions and overall quality of life. A move beyond palliative or comfort care must be an option for this population. There must be a move toward valuation of life and corresponding provision of treatment and examination of developmental gains rather than limited intervention or palliative care for infants with lethal fetal abnormalities. This article presents a call to examine the individual child rather than decision making by diagnosis framed by recommendations from the Convention on the Rights of the Child (CRC) and Convention on the Rights of Persons with Disabilities (CRPD) Medical professionals and parents must work together to ensure medical needs are met and a positive quality of life can be achieved.
\end{abstract}

\section{Keywords}

Trisomy 18; Trisomy 13; Decision-making; Medical interventions; Quality of life

The prevailing viewpoint on children with rare trisomy conditions such as trisomy 18 (t18) and trisomy 13 (t13) is almost uniformly negative. Population based studies describe low survival rates for infants commonly labeled as possessing "lethal fetal anomalies" or who are considered "incompatible with life" [1-6]. Yet, case studies are available highlighting long-term survival [7] as well as parents sharing their experiences online via blogs and Facebook. The paradox is clear. Studies describing large number of children are bleak while individual cases are more positive. The majority of medical professionals look to the former while parents the latter. This often brings conflict when parents request medical interventions such as surgery for their children [8,9]. An additional factor is a rise in prenatal testing and diagnosis. Often, when $\mathrm{t} 18$ or $\mathrm{t} 13$ is confirmed, parents receive recommendations for termination $[10,11]$.

${ }^{*}$ Corresponding author: Deborah A. Bruns, Department of Educational Psychology and Special Education, Southern Illinois University Carbondale, MC4618, Carbondale, IL 62901, USA, Tel: (618) 453-6747; Fax: (618) 453-7110; E-mail: dabruns@siu.edu

Received: November 22, 2012 Accepted: January 11, 2013 Published: January 14, 2013
What is missing in the current discussion is an unbiased examination of surviving children within the context of necessary, rather than "aggressive", medical interventions and overall quality of life. Writers in the areas of palliative care and bioethics largely recommend limited medical intervention or only the provision of comfort care for this population [12-16].

This author undertook a review of the current literature to examine current perspectives on the topic. The parameters were articles related to newborn palliative care in general and focused on rare trisomy conditions and also key articles from the past decade concerning fetal outcomes related to $t 18$ and $\mathrm{t} 13$. Abstracts were then reviewed to verify content. Author searches were also conducted. Finally, recommendations from professional colleagues were sought. Resulting articles and authors suggestions were followed up if not already located with the above described methods. Key quotations were also identified for inclusion in this article.

\section{Current Perspectives}

Little valuation of life is evidenced in the recommendations of Goc et al. [14]. The authors do not recommend caesarean sections or surgery in the immediate postnatal period for newborns with t18. This is in the face of multiple reports such as those from Japan of children living past the age of one year with positive surgical outcomes [17-19]. In addition, at the present time, there is very little literature on developmental outcomes [20,21]. This further impacts and reinforces the prevailing view that focuses on a limited quality of life and arguments against aggressive care [11-13,15]. There must be a move toward valuation of life and corresponding provision of treatment and examination of developmental gains rather than limited intervention or palliative care for infants with "lethal" or "severe" fetal abnormalities.

Concurrently, a significant article by Brown and Guralnick [22] was published stating the importance of components of the Convention on the Rights of the Child (CRC) and Convention on the Rights of Persons with Disabilities (CRPD). For this article's emphasis on advocating for treatment of children with rare trisomy conditions, several points are particularly significant including:

[Article 8: Raising awareness] emphasizes the importance of addressing systemic discriminatory attitudes toward individuals with disabilities, a reality that exists around the world. To that end, the CRPD calls upon States Parties to raise awareness throughout society, including within the family, regarding the rights of individuals with disabilities in order 'to combat stereotypes, prejudices and harmful practices' as well as to develop positive media campaigns and other awareness programs (p. 278).

This is in marked contrast to much of the published work in neonatal nursing and palliative care [8,23-25]. There is discussion of induced abortion and feticide for infants with a severe fetal anomaly such as t18 or t13. Chervanek and McCullough [26] explain "We define 'severe' abnormalities as...compatible with survival in some cases but result in virtual absence of cognitive function, e.g. trisomy 18 ...the potential for cognitive development - and therefore the achievement of human and social goods, e.g. relationships with others 
- are virtually absent" (p. 255). It appears that the authors have not reviewed the case studies or experienced contact with living infants and children with $\mathrm{t} 18$ or $\mathrm{t} 13$. As this author can attest, cognition may be significantly impaired but interactions and relationships with parents, siblings and significant others (e.g., grandparents, teachers) are evidenced in a variety of ways including eye contact, smiling, laughing, reaching and vocalizing by children with these conditions.

Everett and Albersheim [27] describe Baby Smith, an infant with t18. The authors describe a framework to "...increase transparency, dialogue, understanding, and trust, which, in turn, may achieve greater consensus" (p. 55) for medical care decision making. The medical team refused to intubate Baby Smith and did not aggressively treat his unspecified cardiac condition. The infant passed away on the $82^{\text {nd }}$ day of life. What is most disheartening in this case study is the lack of value placed on the infant's life and his parents' wishes for more aggressive treatment. This is also evidenced in the care decisions presented by Bruns and Crosier [28]. The infant, Simon, passed away on the $88^{\text {th }}$ day of life. As the case study indicates, quality of life is only partially dependent on length and medical needs. The infant encountered many difficulties during his brief life but all who came into contact with him were positively affected including medical professionals such as neonatal nurses and a pediatric cardiologist. Their views on medical treatments changed as a result of caring for Simon.

Interestingly, a study by Carey [29] of neonatologists' views on resuscitation of newborns with 118 states "It is critical that the emphasis should remain on fostering the best interest of the infant at every branch of the treatment decision tree" (p. 1109). Yet, this positive outlook is tempered by the authors' recommendation that "Infants with lethal congenital anomalies and profound neurologic impairment continue to have immense inherent worth as human beings, and these infants are without doubt as deserving of love, care, and dignity as any child". However, we contend that having intensive care measures such as intubation and corrective surgery available as potential options for infants with a confirmed lethal trisomy gives the impression to parents that these are reasonable interventions to consider..." (p. 1108).

It is puzzling how both viewpoints can co-exist in terms of identifying treatment options and reinforcing the notion of "lethal congenital anomalies". The authors offer some positive views on decision making but reinforce the negative stance of many in the palliative care field $[9,12,15,16,27]$.

The literature reinforces the statistic of only $10 \%$ of affected infants reaching their first birthday. This percentage is often cited to parents at the time of prenatal diagnosis $[2,6,13]$. Yet, the $10 \%$ amount does not grant the authors cited here exclusive emphasis on the $90 \%$ of non-survivors. Investigations into differences between long-term survivors and non-survivors are absent. There is a dearth of information concerning characteristics of infants who die prior to one month, for example, compared with those living between one and three years. Analyses of these data are especially needed in the face of recommendations for comfort care at birth and palliative care after the immediate newborn period.

Koogler et al. [30] point out, parents should be presented with all possible outcomes to arrive at informed decisions on their infant's behalf rather than being told their infant has a lethal anomaly and should not receive care. In order for guidelines for decision making to be developed, there is a necessity to gather more extensive data (population-based and directly from parents and caregivers), build consensus and, only then, offer recommendations. In fact, Janvier et al. [31] describe positive perspectives from parents coupled with the need to learn more about their experiences raising children with rare trisomy conditions. Without these voices, there will be a continued emphasis on comfort care and non-treatment.

\section{Offering a Positive Viewpoint and Associated Recommendations}

In this author's experience, infants with $\mathrm{t} 18$ and $\mathrm{t} 13$ can and do flourish after cardiac repair and similar types of aggressive medical intervention [21,32]. Along with this data, there is a concomitant need to examine the needs of individual children rather than overreliance on statistical information for decision making. Data collected for the Tracking Rare Incidence Syndromes (TRIS) project includes multiple data points on medical needs and services and developmental outcomes. Two children in the TRIS database are described below:

Annabel was born in March 2005 at 40 weeks gestation via planned c-section. She weighed 1986 grams. Medical issues at birth included respiratory difficulties, heart murmur, ASD, VSD, feeding difficulties and jaundice. She was diagnosed with trisomy 18, 11 days after birth. Currently, Annabel's most pressing issues are kidney and liver functioning as well as related to feeding including PICC and central line concerns. Annabel had ureteral replantation surgery at 19 months. She currently receives medical care in the areas of cardiology, dermatology, gastroenterology, genetics, ophthalmology, pulmonology, and urology. Annabel imitates simple gestures. Annabel associates names of objects with their representation. She also displays preferences for familiar adults.

Arianna was born in June 2006 at 39 weeks gestation via vaginal birth. She weighed 2781 grams. Medical issues at birth included respiratory difficulties, ASD, PDA, VSD, feeding difficulties, and jaundice. She was diagnosed at three days. Arianna required oxygen until the spring of 2012. She is fed via a G-tube. She is also diagnosed with hyperopia and conductive hearing loss. At seven months of age, Arianna had cranial stenososis surgery. She also had her tonsils and adenoids removed at 23 months. Arianna indicates preferences for familiar adults and uses her hands to explore objects. She also interacts during social games.

It is important to note that both children were diagnosed postnatally. "Soft markers" were not identified for Annabel but were present for Arianna. Her family did not consider termination due to their religious beliefs. There is also much additional data on both children describing educational and therapy services and use of assistive items such as a gait trainer and augmentative communication devices.

Most current literature does not provide this type of in-depth discussion of long-term survivors and generally reinforces the findings on early death or negative outcomes. Yet, this information is needed to expand the current knowledge base for professionals and provide parents with more positive, yet realistic (e.g., surgeries, chronic conditions), outcomes. Annabel and Arianna's famililes do not focus on what their daughters cannot do or compare her to their typically developing siblings. They celebrate their children for their personality, temperament and abilities rather than their diagnosis. 
Lantos and Meadow [33] agree that decisions should be made based on an individual infant's response to treatment. Derrington and Dworetz [34] also emphasize an individualized approach coupled with understanding the values of each infant's family. Information from medical professionals is used to arrive at decisions regarding medical interventions. Best interests of child re discussed with information from physicians about possible outcomes. It is unfortunate that the recommendations of Derrington and Dworetz [34] and Lantos and Meadow [33] are not followed as evidenced by Thiele's [35] description of the circumstances she faced with her son with t18. What makes this case particularly discouraging was the absence of compassion after prenatal diagnosis of the condition. The author's account illustrates the medical profession's bias toward a paradigm of medical futility and placing minimal value on a life due to the child's rare trisomy diagnosis. With the continued rise of prenatal testing, the end point of this perspective becomes increasingly disheartening.

Making treatment decisions in the best interests of an infant cannot be effectively done with a "doom and gloom" orientation as is often the case toward this population. How can hope be held when a condition is characterized as "...lethal condition that [is] not curable by intensive care..." [27]? How can parents make decisions without counseling that incorporates a variety of outcomes and an appreciation for quality of life [36-38]? Quality of life is not solely ours to decide. It must be informed by all possible outcomes gleaned from valid research including parent perspectives on their living as well as deceased children. In this author's experience with the TRIS project, the latter group voices an almost uniform point of view of the value of their child's life regardless of how short, medical complications and the like.

Merritt et al. [39] discuss decision making and the need for caseby-case review as the basis for decision-making rather than broad recommendations. Nelson et al. [40] state "although diagnoses of trisomy 13 and 18 are generally assumed to be fatal within days to weeks after birth, a small but significant subgroup of children with trisomy 13 and 18 are alive over the age of 1 year, and at least some of these children receive substantial inpatient hospital care" (p. 874) Yates et al. [41] point to a shift in interventions to address cardiac anomalies based on parent request. Yet, the impact of these studies is minimized by empirical reports emphasizing early mortality [42].

At the present time, there is no definitive consensus on medical interventions and quality of life due to the reasons explained here. A greater effort to collect longitudinal data is a starting point. The TRIS project has up to six years of data for some children and adults (project began in 2007; parents complete annual updates on medical interventions, therapy services etc) There are no similar databases. There continues to be a reliance on adherence to the "gloom and doom" data cited in the literature $[1,2,9,12,24,27]$ rather than a more balanced representation of possible outcomes $[17,19,29,36]$.

\section{Conclusion}

There is a need toward ethical case analysis for medical interventions and determining quality of life for children with t18 and t13 as described by Hentschel et al. [43]. The authors state "more attention should be focused on the parents' information level and on their involvement in the decision-making process" (p. 568). This perspective, along with data indicating the success of medical interventions for this population $[3,19,21,32,44,45]$ deserve greater study and consideration. In addition, changing thoughts on palliative care must be considered on behalf of this population [46]. As Fenton [47] explained, "How easy it is to assume we know what a good quality of life is for anyone other than ourselves. We assess the burdens of care, the impact on siblings, the impact on parental relationships, the impact on finances and the utilization of resources. We perform ethical analyses assuming we truly understand how to apply beneficence or maleficence to a child with trisomy 18 or 13 or any other disorder in which there may be profound disability. As if the child can tell us what he or she is feeling. But we can do our best to assess and treat pain and discomfort. Smiles and laughter need no score pad. We know what they mean. The advice we give may often be centered around our personal notions about quality of life... advocate for a willingness to do whatever it takes, however long it takes, however many consults and team members it takes to fully inform and understand the goals, values and aspirations parents may have for their children. Once we have done that we need to honor the parents by helping them achieve those goals whether it is comfort care alone, a full court press or something in between."

These along with directives established by the "...CRC and CRPD....as the comprehensive articulation of the rights of all individuals with disabilities including infants and young children" discussed by Brown and Guralnick [22] and coupled with Carey's [48] recommendation for a "...balanced approach to counseling families of the newborn with trisomy 18 and 13 at the time of diagnosis and at decision points in management, that is, in the delivery room, newborn nursery and clinic" are words to guide decision making.

The present review was intended to provide a counterpoint to discussions of "incompatibility with life", "lethal diagnoses" and a general unwillingness for "aggressive" interventions. Long-term survivors with rare trisomy conditions must be further studied so that recommendations for their care can be made on an informed basis rather than from a biased perspective inclined toward comfort care or palliative care. Quality of life needs to enter the equation informed by data and parent voices. Children like Annabel and Arianna deserve no less.

\section{References}

1. Brewer CM, Holloway SH, Stone DH, Carothers AD, FitzPatrick DR (2002) Survival in trisomy 13 and trisomy 18 cases ascertained from population based registers. J Med Genet 39: e54.

2. Crider KS, Olney RS, Cragan JD (2008) Trisomies 13 and 18: Population prevalences, characteristics, and prenatal diagnosis, Metropolitan Atlanta, 1994-2003. Am J Med Genet A 146: 820-826.

3. Imataka G, Nitta A, Suzumura $H$, Watanabe $H$, Yamanouchi $H$, et al. (2007) Survival of trisomy 18 cases in Japan. Genet Counsel 18: 303-308.

4. Irving C, Richmond S, Wren C, Longster C, Embleton ND (2011) Changes in fetal prevalence and outcome for trisomies 13 and 18: A population-based study over 23 years. J Matern Fetal Neonatal Med 24: 137-141.

5. Pont S, Robbins J, Bird TM, Gibson J, Cleves M, et al. (2006) Congenita malformations among live born newborns with trisomies 18 and 13. Am J Med Genet A 140: 1749-1756

6. Rasmussen SA, Wong LY, Yang Q, May KM, Friedman JM (2003) Populationbased analyses of mortality in trisomy 13 \& trisomy 18. Pediatrics 111: 777 784.

7. Kelly M, Robinson BW, Moore JW (2002) Trisomy 18 in a 20-year-old woman. Am J Med Genet 112: 397-399.

8. Chervanek F, McCullough LB (2012a) Responsibly counseling women about the clinical management of pregnancies complicated by severe fetal anomalies. J Med Ethics 38: 397-398. 
Citation: Bruns DA (2013) Erring on the Side of Life: Children with Rare Trisomy Conditions, Medical Interventions and Quality of Life. J Genet Disor Genet Rep 2:1.

9. Heuser CC, Eller AG, Byrne JL (2012) Survey of physicians' approach to severe fetal anomalies. J Med Ethics 38: 391-395.

10. Walker LV, Miller VJ, Dalton VK (2008) The health-care experiences of families given the prenatal diagnosis of trisomy 18. J Perinatol 28: 12-19.

11. Wilkinson DJ, Fitzsimons JJ, Dargaville PA, Campbell NT, Loughnan PM, et al. (2006) Death in the neonatal intensive care unit: Changing patterns of end of life care over two decades. Arch Dis Child Fetal Neonatal Ed 91: F268-F271.

12. Breeze ACG, Lees CC, Kumar A, Missfelder-Lobos HH, Murdoch EM (2007) Palliative care for prenatally diagnosed lethal fetal abnormality. Arch Dis Child Fetal Neonatal Ed 92: F56-F58.

13. Courtwright AM, Laughon MM, Doron MW (2011) Length of life and treatment intensity in infants diagnosed prenatally or postnatally with congenital anomalies considered to be lethal. J Perinatol 31: 387-391.

14. Goc B, Walencka Z, Włoch A, Wojciechowska E, Wiecek-Włodarska D, et al. (2008) Trisomy 18 in neonates: Prenatal diagnosis, clinical features, therapeutic dilemmas and outcome. J Appl Genet 47: 165-170.

15. Munson D, Leuthner SR (2007) Palliative care for the family carrying a fetus with a life limiting diagnosis. Pediatr Clin North Am 54: 787-798.

16. Romesberg TL (2007) Building a case for neonatal palliative care. Neonata Netw 26: 111-115.

17. Kaneko Y, Kobayashi J, Yamamoto Y, Yoda H, Kanetaka Y, et al. (2008) Intensive cardiac management in patients with trisomy 13 or trisomy 18 . Am J Med Genet A 146: 1372-1380.

18. Kobayashi J, Kaneko Y, Yamamoto Y, Yoda H, Tsuchiya K (2010) Radical surgery for a ventricular septal defect associated with trisomy 18. Gen Thorac Cardiovasc Surg 58: 223-227.

19. Kosho T, Nakamura T, Kawame H, Baba A, Tamura M, et al. (2006) Neonata management of trisomy 18: Clinical details of 24 patients receiving intensive treatment. Am J Med Genet A 140: 937-944.

20. Baty BJ, Jorde LB, Blackburn BL, Carey JC (1994) Natural history of trisomy 18 and trisomy 13: II. Psychomotor development. Am J Med Genet 49: 189194

21. Bruns D (2011) Birth history, physical characteristics, and medical conditions in long-term survivors with full trisomy 13. Am J Med Genet A 155: 26342640.

22. Brown SE, Guralnick MJ (2012) International Human Rights to early intervention for infants and young children with disabilities: Tools for global advocacy. Infants Young Child 25: 270-285.

23. Catlin A (2010) Trisomy 18 and choices. Adv Neonatal Care 10: 32.

24. Chervanek FA, McCullough LB (2009) An ethically justified practical approach to offering, recommending, performing and referring for induced abortion and feticide. Am J Obstet Gynecol 201: 560e 1-6.

25. Guibilini A, Minerva F (2012) After-birth abortion: Why should the baby live? $J$ Med Ethics.

26. Chervanek FA, McCullough LB (2012) Ethical dimensions of fetal neurology Semin Fetal Neonatal Med 17: 252-255.

27. Everett BJ, Albersheim SG (2011) Ethical care for infants with conditions not curable with intensive care. J Clin Ethics 22: 54-60

28. Bruns DA, Crosier $S$ (in review) Caring for an infant with trisomy 18: Sharing a new perspective.

29. Carey JC (2008) Attitudes of neonatologists toward delivery room management of confirmed trisomy 18: Potential factors Influencing a changing dynamic. Pediatrics 123: e547-e548.

30. Koogler TK, Wilfond BS, Ross LF (2003) Lethal language, lethal decisions. Hastings Cent Rep 33: 37-41.

31. Janvier A, Farlow B, Wilfond BS (2012) The experience of families with children with trisomy 13 and 18 in social networks. Pediatrics 130: 293 -298.

32. Bruns DA (2010) Neonatal experiences of newborns with full Trisomy 18. Adv Neonatal Care 10: 25-31.
33. Lantos JD, Meadow WL (2011) Costs and end-of-life care in the NICU: Lessons for the MICU? J Law Med Ethics 39: 194-200.

34. Derrington SF, Dworetz AR (2011) Confronting ambiguity: Identifying options for infants with trisomy 18. J Clin Ethics 22: 338-44.

35. Thiele $P$ (2010) He was my son, not a dying baby. J Med Ethics 36: 646-647.

36. Janvier A, Okah F, Farlow B, Lantos JD (2011) An infant with trisomy 18 and a ventricular septal defect. Pediatrics 127: 1-6.

37. Lakovschek IC, Streubel B, Ulm B (2011) Natural outcome of trisomy 13 , trisomy 18 , and triploidy after prenatal diagnosis. Am J Med Genet A 155 : 2626-2633.

38. Lin H, Lin S, Chen Y, Hung H, Kao H, et al. (2006) Clinical characteristics and survival of trisomy 18 in a medical center in Taipei, 1988-2004. Am J Med Genet A 140: 945-951.

39. Merritt TA, Catlin A, Wool C, Peverini R, Goldstein M, et al. (2012) Trisomy 18 and Trisomy 13: Treatment and management decisions. Neoreviews 13: e40 -e48.

40. Nelson KE, Hexem KR, Feudtner C (2012) Inpatient hospital care of children with trisomy 13 and trisomy 18 in the United States. Pediatrics 129: 869 -876.

41. Yates AR, Hoffman TM, Shepherd E, Boettner B, McBride KL (2011) Pediatric sub-specialist controversies in the treatment of congenital heart disease in trisomy 13 or 18. J Genet Couns 20: 495-509.

42. Burke AL, Field K, Morrison JJ (2012) Natural history of fetal trisomy 18 after prenatal diagnosis. Arch Dis Child Fetal Neonatal Ed.

43. Hentschel R, Lindner K, Krueger M, Reiter-Theil S (2006) Restriction of ongoing intensive care in neonates: A prospective study. Pediatrics 18: 563 -569 .

44. Baty BJ, Blackburn BL, Carey JC (1994) Natural history of trisomy 18 and trisomy 13: Part B Growth, physical assessment, medical histories, survival, and recurrence risk. Am J Med Genet 49: 175-188.

45. Graham EM, Bradley SM, Shirali GS, Hills CB, Atz AM, et al. (2004) Effectiveness of cardiac surgery in trisomies 13 and 18 (from the Pediatric Cardiac Care Consortium) Am J Cardiol 93: 801-803.

46. Liben S, Papadatou D, Wolfe J (2008) Paediatric palliative care: Challenges and emerging ideas. Lancet 371: 852-864.

47. Fenton LJ (2011) Trisomy 13 and 18 and quality of life: Treading "softly". Am J Med Genet A 155: 1527-1528.

48. Carey JC (2012) Perspectives on the care and management of infants with trisomy 18 and trisomy13: Striving for balance. Curr Opin Pediatr 24:672-678.

\section{Author Affiliation}

Top

${ }^{1}$ Department of Educational Psychology and Special Education, Southern Illinois University Carbondale, MC-4618 Carbondale, IL 62901, USA

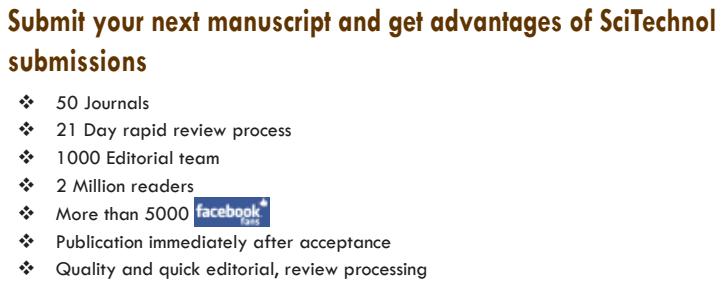

Submit your next manuscript and get advantages of SciTechnol submissions

* 50 Journals

* 21 Day rapid review process

* 1000 Editorial tean

* 2 Million readers

* More than 5000 facebogk

* Publication immediately after acceptance

* Quality and quick editorial, review processing

Submit your next manuscript at • www.scitechnol.com/submission 